\title{
Assessment of Fomites and Infection Risk to Seniors in Recreational Curling
}

\author{
Elliot Spicer ${ }^{1}$, Helen Heacock ${ }^{2}$
}

1 Lead author, B. Tech Student, School of Health Sciences, British Columbia Institute of Technology, 3700 Willingdon Ave, Burnaby, BC V5G 3H2

2 Supervisor, School of Health Sciences, British Columbia Institute of Technology, 3700 Willingdon Ave, Burnaby, BC V5G 3H2

\begin{abstract}
Background: Seniors participate in sports to improve physical, mental, and social health; however, such activities may increase the risk of illness and injury. Curling is popular in this age group because it is physically manageable, strategic, and provides social connection. Certain factors in curling such as handshaking, play during the flu season, and shared contact with curling stones suggest an increased risk of disease transmission. The purpose of this study was to determine the qualitative risk of communicable enteric disease transmission due to shared contact with curling stone handles in a senior men's curling league.
\end{abstract}

Methods: 3M $\mathrm{M}^{\mathrm{TM}}$ Quick Swabs were used to sample 22 curling stone handles for total coliforms before a senior's league game. To analyze microbial shedding during gameplay, the same 22 handles were sampled after the game. Samples were plated on $3 \mathrm{M}^{\mathrm{TM}}$ Petrifilm ${ }^{\mathrm{TM}}$ Coliform Count Plates and incubated at $30^{\circ} \mathrm{C} \pm 1^{\circ} \mathrm{C}$ for 24 hours \pm 2 hours. Colonies were enumerated in units of CFU (colony forming units) $/ \mathrm{cm}^{2}$. Ambient and handle surface temperatures were measured, and curler hygiene-related behaviours documented.

Results: Total coliform counts for all samples were $0 \mathrm{CFU} / \mathrm{cm}^{2}$. The ambient temperature was $6.6^{\circ} \mathrm{C}$ pre-game, and $8.0^{\circ} \mathrm{C}$ post-game. Mean handle surface temperature was $3.6^{\circ} \mathrm{C}$. Hygiene behaviours of concern were hand-face contact, handkerchief/tissue use, and handshaking.

Conclusion: There is low risk of enteric disease transmission due to shared contact with curling stone handles by male curlers 55 years and older. Absence of coliforms may have been due to adequate player hygiene, transference of microbial load before sampling, error, or environmental conditions. Health promotion and education can reduce the infection risk elevated by poor hand hygiene, face contact, and handshaking in senior's curling, thereby protecting the health and welfare of all participants.

Keywords: Curling, handle, sport, coliform, pathogen, seniors, enteric, fomite, CFU, illness 


\section{INTRODUCTION}

A direct relationship between increasing age and susceptibility to infections has been established through medical research. Changes in the immune system, body functionality and anatomy, and increased exposure to infection in care facilities and hospitals are factors (US Institute of Medicine, 1992). Seniors can improve their health outlook by participating in recreational activities. In people older than 65 , physical activity has been strongly linked to decreased medical costs (Woolcott, Ashe, \& Miller, 2010). Getting regular exercise offers many benefits to older populations; however, such activities may also expose seniors to communicable disease or injury. With manageable physical demands, strategy, and social connection, recreational curling is growing in popularity among this age group. However, there are aspects of the game that raise concerns about hygiene and disease transmission.

A curling stone, shown in Figure 1 (CCS Co., n.d.), has a hard-plastic handle which is held by Figure 1. Curling stone multiple players during a game; It is a hightouch surface. This shared contact indicates a potential for handles to act as fomites, inanimate objects that indirectly spread disease. Play occurs exclusively in the fall and winter when viral infection risk is greater. Handshaking is an essential part of game etiquette, but can further increase transmission. The use of handkerchiefs or tissues due to illness and warm to cold transitions is common. This can transfer infectious secretions to hands, surfaces, and other players. These factors indicate that seniors in recreational curling may be at increased risk of disease. This research establishes how curling stone handle contact and player behaviour contributes to that risk.

The purpose was to determine the qualitative risk of enteric disease transmission due to shared contact with curling stone handles in a senior men's curling league. The extent of pathogen shedding from players was assessed by enumerating indicator microorganisms on the handles before and after gameplay. These quantitative results were used to indicate the role of curling stone handles in enteric pathogen harbourage and spread, which was translated into a qualitative risk designation. Temperature and curler hygiene behaviours were also recorded. The overall goal was to protect the welfare of seniors, support active lifestyles, and educate players about potential health risks. 


\section{EVIDENCE REVIEW}

Non-communicable disease

Literature relating morbidity and age prioritizes non-communicable disease (NCD) such as diabetes and stroke. In their contribution to the work of Beard, et al (2012), "Global Population Ageing: Peril or Promise?" Williams \& Krakauer (2012) discuss NCD in seniors, stating that the high frequency and severity of such conditions justify their study. In most cases, treatment slows progress but does not lead to full recovery (Williams \& Krakauer, 2012). This contrasts with communicable disease (CD) which, despite potentially severe health effects, is lower in incidence and has a greater prospect of full recovery. This emphasis on NCD is reflected in countless papers the world over. An Indian study, examining increased life expectancy and the ageing population, confirmed that NCD are the major cause of illness and death for senior citizens in India (Kanitkar, Kalyan, Gaikwad, Deshmukh, \& Saha, 2018). Further, Feng, et al (2014) noted a growing trend of NCD cases in elderly populations in China and throughout the world. The literature suggests that resources are best allocated to the study of severe, widespread, and complex diseases. This is sound reasoning; however, $\mathrm{CD}$ such as foodborne infections also cause illness and fatality in seniors, albeit with lesser intensity. Health hazards more limited in scope or impact are still a threat, and should not be overlooked.

\section{Infection control in sport}

Most research on infection risk in sports and recreation, for instance that of Ahmadinejad, Alijani, Mansori, \& Ziaee (2014), and Peterson, Nash, \& Anderson (2018), examines close-contact sports such as wrestling. Fomites in sport appear to be a low priority for research, but have seen some contributions. Kreitenberg (2012), an inventor from Los Angeles, California, submitted a patent application for a "Sports Ball Sterilizer." He states that disease spread in athletics is a growing concern. Suspension of the Tokyo 2020 Olympic Games due to the COVID-19 (novel coronavirus disease) pandemic and the gathering of people from across the globe reflects this assertion. Kreitenberg (2012) declares the sports ball as the "ultimate fomite" due to repeated contact by multiple players; a characteristic that also apply to curling stones.

\section{Curling resources and outbreaks}

Curling Canada, the national sanctioning body, offers no standing suggestions, policies, or statements about sanitation, hygiene, or infection risk, but urged curling 
centres to suspend play during the COVID19 crisis. This was imperative for social distancing, and as a response to a cluster of COVID-19 cases at a curling tournament. The annual event in Edmonton hosted 72 Canadian physicians in March 2020. 13 attendees tested positive for the illness and others were advised to self-quarantine (CBC News, 2020). Contact with people and hightouch surfaces were probable factors. Respiratory viruses like SARS-CoV-2 (novel coronavirus) pose a greater risk of morbidity and death in elderly male populations (Polglase, Foster, \& Mezzofiore, 2020). This reveals the potential for viral respiratory illness in senior men's curling, stressing the need for prevention. In addition, recurring outbreaks of gastrointestinal (GI) illness occurred at the Scotties Tournament of Hearts in 1999, 2012, and 2014. The resilience of substitute curlers and those playing while ill was celebrated, but modes of transmission and health-related factors were not studied or even mentioned (Curling Canada, 2012; The Canadian Press, 2014). Evidence implicates viral enteric illness, which is spread rapidly via fomite and person-to-person contact. Young high-performance athletes were unable to compete due to this outbreak; A similar event in an elderly population could be devastating. These repeat incidents indicate a need for targeted research.

\section{Pathogens and hard surface fomites}

Viral disease was the focus of most research on $\mathrm{CD}$ transmission via fomites. With respect to bacteria, analyses of methicillin resistant Staphylococcus aureus (MRSA) were common. Boone \& Gerba (2005) studied the prevalence of Influenza A virus on home and daycare surfaces, while Desai, et al. (2011) examined fomites and MRSA spread. In both papers, and many similar works, non-porous metal and plastic fomites were sampled. Boone and Gerba (2005) sampled bathroom faucets, doorknobs, and phone receivers. Desai et al (2011) tested razor blades and plastic toy blocks, the latter shown to have the highest bacterial recovery. Further, a journal article reported that SARS-CoV-2 can remain viable for up to 72 hours on plastic surfaces (Holbrook, et al., 2020). Experts consider microbiological sampling of hard surfaces to be a practical function. This validates the research methods, in which hard plastic is sampled.

\section{Sampling at a child care facility}

BCIT student Chiu (2017) researched links between sanitation and disease in a child care facility, sampling for bacteria on wooden toy blocks before and after 
sanitizing. Similar to this work, Chiu (2017) included a vulnerable population, pre- and post-intervention sampling of hard surfaces, and total coliform enumeration. No coliforms were obtained from the toy blocks before or after sanitizing. Chiu (2017) reasoned that good facility hygiene, unsuitable methods, or experimental error may have contributed. The nature of the data inspires a comparable study, to see if using similar methods in a new context would produce different results.

\section{Summary}

$\mathrm{CD}$ is a health risk to seniors, infection in sport should be studied, hard surface testing is feasible, outbreaks in curling have occurred, and past research has left lingering questions. Based on the collective literature, this work serves a valuable purpose.

\section{MATERIALS AND METHODS}

Total coliform (TC) sampling, culturing, and enumeration was performed. TC bacteria indicate the presence of enteric pathogens such as norovirus or E. coli $\mathrm{O} 157: \mathrm{H} 7$. Samples and data were collected during senior's league play (male 55+) at the Peace Arch Curling Centre (PACC) in White Rock, British Columbia. All curling stones were of standard design, weight, and material (World Curling Federation, 2008).
To report colony forming units $(\mathrm{CFU}) / \mathrm{cm}^{2}$, the handle was treated as a cylinder, and the surface area computed using the relevant formula (SA $\left.=2 \pi r^{2}+2 \pi r h\right)$. Diameter $(2 r)$ and length (h) measurements were taken from a random curling stone using a sewing tape measure.

On January 22, 2020, one hour prior to game start at 09:00, 22 curling stone handles were sampled with $3 \mathrm{M}^{\mathrm{TM}} 1.0 \mathrm{~mL}$ Quick Swabs, following steps 2-6 of the $3 \mathrm{M}^{\mathrm{TM}}$ Quick Swabs standard methods for wet swabbing (3M, 2014). Complete samples were temperature controlled using ice packs. Ambient temperature was taken using a Traceable digital probe thermometer, and an Oakton Infrapro infrared (IR) thermometer was used to measure handle surface temperature.

70 minutes before game end at 11:00, player hygiene behaviours were recorded. Once play finished, ambient temperature and 22 post-game samples were retrieved. Final surface temperatures could not be taken due to time constraints. A total of 44 samples were obtained and always held at $\leq 8^{\circ} \mathrm{C}$ $\left(46^{\circ} \mathrm{F}\right)$ as required by standard methods.

In a laboratory at BCIT Burnaby Campus later that day, all 44 samples were plated and cultured on $3 \mathrm{M}^{\mathrm{TM}}$ Petrifilm ${ }^{\mathrm{TM}}$ Coliform 
Count Plates in accordance with steps 7-9 of $3 \mathrm{M}^{\mathrm{TM}}$ Quick Swabs standard methods, and the following sections of $3 \mathrm{M}^{\mathrm{TM}}$ Petrifilm ${ }^{\mathrm{TM}}$ standard methods: Plating steps 1-5, Incubation, and Specific Instructions for Validated Methods. Petrifilm ${ }^{\mathrm{TM}}$ plates were incubated at $30^{\circ} \mathrm{C} \pm 1^{\circ} \mathrm{C}$ for 24 hours \pm 2 hours in two stacks of 20 , and one stack of 4 (3M, 2015). Cultured plates were enumerated the following day, referencing the $3 \mathrm{M}^{\mathrm{TM}}$ Petrifilm ${ }^{\mathrm{TM}}$ E. coli/Coliform Count Interpretation Guide (3M, 2017).

\section{RESULTS}

Surface area calculations for a curling stone yielded a continuous numerical figure from the formula for a cylinder $\left(\mathrm{SA}=2 \pi \mathrm{r}^{2}+\right.$ $2 \pi \mathrm{rh})$. At a measured length of $11.5 \mathrm{~cm}$, and diameter of $2 \mathrm{~cm}(\mathrm{r}=1 \mathrm{~cm})$, the handle surface area was $78.50 \mathrm{~cm}^{2}$.
Enumeration of cultured plates resulted in discrete numerical coliform counts of 0 $\mathrm{CFU} / \mathrm{cm}^{2}$ for all samples. The final sample data are summarized in Table 1 using basic descriptive statistics from Microsoft Excel. Inferential statistics were not performed.

Final coliform counts were analyzed with respect to null $\left(\mathrm{H}_{0}\right)$ and alternative $\left(\mathrm{H}_{\mathrm{a}}\right)$ hypotheses, abbreviated in Table 2 . The sample results indicate that the null hypothesis cannot be rejected.

The ambient temperature in the playing area was measured at $6.6^{\circ} \mathrm{C}$ before the 09:00 game, then $8.0^{\circ} \mathrm{C}$ after the game. Handle surface temperatures had a range of $2.0^{\circ} \mathrm{C}$, with a mean of $3.6^{\circ} \mathrm{C}$. Continuous numerical temperature data is presented in Table 3.

Table 1. Descriptive statistics from Microsoft Excel for total coliform data.

\begin{tabular}{r|cc} 
Parameter & Pre-game (CFU) & Post-game (CFU) \\
\hline Mean & 0 & 0 \\
Median & 0 & 0 \\
Mode & 0 & 0 \\
Standard Error & 0 & 0 \\
Standard Deviation & 0 & 0 \\
Sample Variance & 0 & 0 \\
Range & 0 & 0 \\
Minimum & 0 & 0 \\
Maximum & 0 & 0 \\
Sum & 0 & 0 \\
Observations & 22 & 22
\end{tabular}


Table 2. Null and alternative hypotheses for total coliform data.

\begin{tabular}{l|l}
$\mathrm{H}_{0}$ & Mean post-game total coliform count $\leq$ mean pre-game total coliform count \\
\hline $\mathrm{H}_{\mathrm{a}}$ & Mean post-game total coliform count $>$ mean pre-game total coliform count
\end{tabular}

Table 3. Ambient and pre-game handle surface temperature data.

\begin{tabular}{|c|c|c|c|}
\hline \multicolumn{4}{|c|}{ Ambient } \\
\hline Pre-game $\left({ }^{\circ} \mathrm{C}\right)$ & 6.6 & Post-game $\left({ }^{\circ} \mathrm{C}\right)$ & 8.0 \\
\hline \multicolumn{4}{|c|}{ Handle Surface } \\
\hline Sample & Temperature $\left({ }^{\circ} \mathrm{C}\right)$ & Sample & Temperature $\left({ }^{\circ} \mathrm{C}\right)$ \\
\hline 1 & 3.9 & 12 & 3.5 \\
\hline 2 & 3.3 & 13 & 3.9 \\
\hline 3 & 4.3 & 14 & 3.6 \\
\hline 4 & 2.3 & 15 & 3.8 \\
\hline 5 & 4.1 & 16 & 3.4 \\
\hline 6 & 3.4 & 17 & 3.4 \\
\hline 7 & 3.5 & 18 & 3.1 \\
\hline 8 & 3.9 & 19 & 3.8 \\
\hline 9 & 3.8 & 20 & 3.3 \\
\hline 10 & 3.9 & 21 & 4.0 \\
\hline 11 & 3.6 & 22 & 3.5 \\
\hline
\end{tabular}

Table 4. Hygiene-related player behaviour observed on the day of sampling.

\section{Behaviour Category}

Curling stone contact

- Bare hand contact: touching, twirling, firm grip

- Stick delivery devices used (plastic device-handle contact)

\begin{tabular}{r|ll}
\cline { 2 - 3 } Glove use & $\begin{array}{l}\text { Often: when sweeping/calling shots } \\
\text { Hand-face contact }\end{array}$ & Frequent donning/removal of delivery hand glove. \\
\cline { 2 - 3 } Tissue use & $\begin{array}{l}\text { Bare hand contact with nose, mouth, hair - followed by } \\
\text { handle contact (six instances) }\end{array}$ \\
\cline { 2 - 3 } Player-player contact & $\begin{array}{l}\text { Bare-handed for wiping nose (twice) } \\
\text { Handkerchief use/re-use (once) }\end{array}$ \\
\cline { 2 - 3 } Other & \begin{tabular}{l} 
Bare handed/gloved handshaking (customary) \\
\cline { 2 - 3 }
\end{tabular} & $\begin{array}{l}\text { Wiping hands off on clothing, then handle contact (once) } \\
\text { Use of water cooler (paper cups, high-touch spigot handle) }\end{array}$
\end{tabular}


The hygiene-related behaviours of senior's league curlers, observed during the 09:00 game, are categorized in Table 4 above. These include many actions commonly known to increase disease spread.

\section{DISCUSSION}

Based on the absence of indicator organisms, it is unlikely that any of the 44 handles were contaminated with enteric pathogens at the time of sampling. The risk for enteric disease transmission promoted by pathogen shedding and shared contact with handle surfaces in the senior's league is low.

The risk of illness from environmental exposure to pathogenic bacteria is greater when the cell population reaches infectious dose; the cell number threshold for human illness specific to bacterial species. On warm, porous, nutrient-rich media, most bacteria quickly multiply to reach infectious dose, but reproduction is slowed on hard, dry surfaces below $4.0^{\circ} \mathrm{C}$. With cold, plastic handles restricting growth; presence, exposure, and the odds of cell capture via swabbing were reduced. In contrast to bacteria, evidence suggests that cold temperatures may improve the survival, and spread of viruses (Eske, 2018), which implicates viral respiratory disease as a notable hazard in seniors curling.
The transfer of idle bacteria from the handle to growth-supportive media can occur. By touching the handle, cells can be transferred to the skin, and subsequently to other areas or items that promote growth. Touching the mouth and nose can introduce pathogens into the body, posing a risk for infection.

If players did not deposit quantifiable coliforms at the time of sampling then zero counts are logical. Hand hygiene may have been adequate or handles simply were not contaminated at the time. If deposition did occur, player and equipment contact may have influenced microbial load by applying friction to handles, potentially removing matter from the surface. Continuous transference and disruption of colonies was possible. The instance of colonization may have been so fleeting that its capture relied more on chance than expected.

Temperature data reflects logical environmental changes and conditions. The initial ambient reading increased after one game due in part to the presence and movement of players. Handles had lower temperatures than ambient because of their close proximity to the ice. The mean surface temperature of $3.6^{\circ} \mathrm{C}$ is less than $4.0^{\circ} \mathrm{C}$, the temperature under which most microbial growth is suppressed, supporting the 
assertion that arena conditions affect sampling and exposure.

Many curler behaviours are concerning from a health viewpoint. Hand-face contact and handkerchief/tissue use were often preceded and followed by handle contact. Once colonized by a pathogen, hand contact with the mouth or nose provides direct entry to the body, increasing infection risk. If already ill, infectious agents can be transmitted from the mouth or nose to a curling stone or other players through hand contact, spreading the illness. Tissue use transfers mucous and saliva onto the hands, then to people and surfaces. Surface deposition of mucous, saliva, and skin cells can also promote microbial growth on that surface.

Handshaking rapidly facilitates person to person disease transmission, making it a significant factor where illness appears in the sport. As a hallmark of curling culture, handshaking would be difficult to eliminate. The risk is more practically addressed through good hand hygiene. The behaviours observed can increase disease spread, indicating general pathogen exposure risk to male curlers 55+ exists. Promoting good hygiene during play is recommended.

Chiu's (2017) toy hygiene study can be revisited. Using nearly identical methods, neither Chiu's (2017) research nor this study retrieved positive samples. It can only be speculated if this is due to proper hygiene in both cases, error or other variables. In case a pattern of error in method is emerging, it is recommended that those with similar goals employ alternate means for assessing fomites, as a substitution or comparison for $3 \mathrm{M}^{\mathrm{TM}}$ equipment.

COVID-19 cases from an Edmonton curling event and recurring GI illness at the Scotties Tournament of Hearts suggest curling activities may have aided transmission. This study confirms that fomites cannot be ruled out, but handshaking with ill players, poor hand hygiene, and face contact likely posed a greater risk. In a situation where a curling stone handle contains an infectious dose of bacteria; thorough hand washing by curlers and avoidance of handshaking and face contact would still break the chain of disease transmission. Person to person spread and routes of entry would be eliminated, and pathogens on the hands would be promptly removed. Mitigating adverse effects of handshaking, poor hand hygiene, and face contact is a sound approach for infection control in curling. This accounts for the possibility that handles are significant in disease spread, even though this study did not confirm that. 
Based on literature, data, and public health, disease, and microbiological theory, the results are considered valid. Techniques complied with standard methods and introduced no discernible error. The low risk designation for enteric pathogen spread from handle contact applies to curling and all participants in the sport. These data and conclusions cannot be applied to other sports and their participants without further research.

\section{KNOWLEDGE TRANSLATION}

To educate curling club members about infection risk and personal hygiene, a single page bulletin is recommended. Content must include research scope, results, health significance, and disease prevention measures. This communication should be posted on the senior's league bulletin board. Emphasis must be placed on conveying proper handwashing technique, cough and sneeze etiquette, avoiding face contact, and handshaking alternatives.

Making hand sanitizer accessible during gameplay will allow curlers to practice good hygiene in the absence of hand washing facilities. This is an affordable, low risk measure that can be introduced at any time. As COVID-19 intensified, PACC posted signage and provided hand sanitizer. Closure soon followed. Management did not state whether these measures would remain once the pandemic de-escalated.

\section{LIMITATIONS AND AMENDMENTS}

Time and funding were not available for more samples and tests like adenosine triphosphate (ATP) and viral recovery. After project completion, two amendments were identified.

ATP, an energy molecule in living cells, was deemed to be an ineffective marker for enteric pathogen exposure risk; however, testing for ATP alongside TC in a pilot study would have been ideal. Based on the pilot results, either one or both of the tests would be used. Despite reservations over ATP as an indicator, this method would have tested its efficacy and provided a more holistic hygiene assessment.

Incubating plates containing a known solution of water and viable coliforms would have verified the culturing technique and equipment. Preparation would be identical to field samples. If coliform-containing plates produced visible colonies, then process validity would be confirmed.

\section{FUTURE RESEARCH}

Study viral respiratory disease transmission in recreational curling: 
- Virus recovery from surfaces

- Behaviour and environmental factors

Assess the risk of injury or illness in other recreational activities popular with seniors:

- Lawn bowling, pickleball, aquatics

- Injury/illness risk and prevention

- Educate seniors, families, caregivers

Evaluate high-touch objects and hygiene at public bowling alleys:

- Microbial sampling of bowling ball surface and finger/thumb holes

- Only include public use equipment

\section{CONCLUSION}

Seniors who participate in curling to remain active and social should understand the associated hazards. This study examined the microbiological hazards. With no coliforms recovered from 44 curling stone handles, it was concluded that the risk of enteric illness to male curlers $55+$ from shared contact with curling stone handles is low. This does not mean that illness and injury risk is nonexistent, nor that curling stone handles do not facilitate disease spread. Handles are not the primary factor in the transmission of enteric pathogens shed by curlers.

Handshaking, face touching, and tissue use without proper handwashing appear to be of greater concern. Players must be educated about these risky behaviours and how to break the chain of transmission. Proper handwashing is the most simple and effective way to prevent illness, and should be done before and after play. Promoting other hygienic behaviours and providing hand sanitizer is also recommended. Curling is an enjoyable sport that can help people of all ages stay physically and mentally active. Enteric pathogen exposure carries a low risk, and should not dissuade anyone from curling for the first time or continuing to play. This research is intended to support and inform future studies on infection control and sports hygiene, with the primary goal to protect public health and encourage active lifestyles.

\section{ACKNOWLEDGMENTS}

The lead author thanks BCIT Laboratory Technician Fred Shaw for providing equipment and work space. Thanks to BCIT Instructor Dale Chen for assisting with initial planning.

\section{COMPETING INTEREST}

The lead author declares a competing interest as an active participant in recreational curling at Peace Arch Curling Centre. No funding or direction was received from any person therein. 


\section{REFERENCES}

3M. (2014, November). 3M Quick Swab Product Instructions. Retrieved from 3M Website: https://multimedia.3m.com $/ \mathrm{mws} / \mathrm{med}$ ia/1030809O/quick-swab-productinstructions.pdf

3M. (2015, August). 3M Petrifilm ${ }^{\mathrm{TM}}$ Product Instructions. Retrieved from 3M Website:

https://multimedia.3m.com/mws/med ia/729710O/product-instructions-3mpetrifilm-coliform-count-plate.pdf

3M. (2017). 3M Petrifilm ${ }^{\mathrm{TM}}$ E. coli/Coliform Count Plate Interpretation Guide. Retrieved from 3M Website: http://multimedia.3m.com/mws/medi a/236246O/petrifilm-ecoli-coliforminterpretation-guide.pdf

Ahmadinejad, Z., Alijani, N., Mansori, S., \& Ziaee, V. (2014). Common SportsRelated Infections: A Review on Clinical Pictures, Management and Time to Return to Sports. Asian Journal of Sports Medicine.

Beard, J., Biggs, S., Bloom, D., Fried, L., Hogan, P., Kalache, A., \& Olshansky, J. (2012). Global Population Ageing: Peril or Promise? .

Boone, S. A., \& Gerba, C. P. (2005). The occurrence of influenza A virus on household and day care center fomites.

CBC News. (2020, March 21). 13 cases of COVID-19 linked to curling bonspiel attended by doctors from across western Canada. Retrieved from
CBC News Website:

https://www.cbc.ca/news/canada/sas katchewan/13-covid-19-casesdoctors-attended-curling-bonspiel1.5505940

CCS Co. (n.d.). Curling Stones \& Handles. Retrieved from Canadian Curling Stone Co.: https://canadacurlingstone.on.ca/

Chiu, J. (2017). Mean difference of coliform counts in relation to sanitation frequencies at the Simon Fraser University Childcare Society. BCIT Environmental Health Journal.

Retrieved from https://circuit.bcit.ca/repository/islan dora/object/repository\%3 A387?solr nav $\% 5 \mathrm{Bid} \% 5 \mathrm{D}=\mathrm{f} 8 \mathrm{e} 066 \mathrm{a} 2514 \mathrm{cac} 378$ 2bd\&solr_nav $\% 5$ Bpage $\% 5 \mathrm{D}=0 \&$ solr nav $\% 5$ Boffset $\% 5 \mathrm{D}=1$

Curling Canada. (2012). Manitoba, Saskatchewan defy flu bug. Retrieved from Curling Canada Website: https://www.curling.ca/blog/2012/02 /21/manitoba-saskatchewan-defy-flubug/

Desai, R., Pannaraj, P. S., Agopian, J., Sugar, C. A., Liu, G. Y., \& Miller, L. G. (2011). Survival and transmission of community-associated methicillinresistant Staphylococcus aureus from fomites.

Eske, J. (2018, October 23). What's the link between cold weather and the common cold? Retrieved from Medical News Today: https://www.medicalnewstoday.com/ articles/323431

Feng, L., Li, P., Wang, X., Hu, Z., Ma, Y., Tang, W., \& Wang, F. (2014). 
Distribution and determinants of non communicable diseases among elderly uyghur ethnic group in xinjiang, china. PLoS One.

Holbrook, M. G., Gamble, A., Williamson, B. N., Tamin, A., Harcourt, J. L., Thornburg, N. J., . . Morris, D. H. (2020, March 17). Aerosol and Surface Stability of SARS-CoV-2 as Compared with SARS-CoV-1. The New England Journal of Medicine. doi:10.1056/NEJMc2004973

Kanitkar, S., Kalyan, M., Gaikwad, A., Deshmukh, S., \& Saha, R. (2018). Prevalence of Non Communicable Diseases in Elderly. Journal of The Indian Academy of Geriatrics.

Kreitenberg, A. (2012). United States Patent: Sports Ball Sterilizer. Retrieved from Patent Images Web site: https://patentimages.storage.googlea pis.com/94/49/40/2e90ce6800b42f/U S8193515.pdf

Peterson, A. R., Nash, E., \& Anderson, B. (2018). Infectious Disease in Contact Sports. Sports Health: A Multidisciplinary Approach.

Polglase, K., Foster, M., \& Mezzofiore, G. (2020, March 24). Here's why the coronavirus may be killing more men than women. The US should take note. Retrieved from CNN Website: https://www.cnn.com/2020/03/24/he alth/coronavirus-gender-mortalityintl/index.html

Spicer, E. (2020). Assessment of Fomites and Infection Risk to Seniors in Recreational Curling. British
Columbia Institute of Technology (BCIT).

The Canadian Press. (2014). B.C. unfazed by flu bug at Tournament of Hearts. Retrieved from CBC Website: https://www.cbc.ca/sports/olympics/ winter/curling/b-c-unfazed-by-flubug-at-tournament-of-hearts1.2522941

US Institute of Medicine. (1992). Risk Factors for Infection in the Elderly. The Second Fifty Years: Promoting Health and Preventing Disability. Retrieved from https://www.ncbi.nlm.nih.gov/books/ NBK235606/

Williams, R., \& Krakauer, R. (2012). The Challenge of Non-Communicable Diseases and Geriatric Conditions.

Woolcott, J., Ashe, M., \& Miller, W. (2010). Does physical activity reduce seniors' need for healthcare?: a study of 24281 Canadians. British Journal of Sports Medicine.

World Curling Federation. (2008, June). The Rules of Curling and Rules of Competition. 